\title{
Incidence and Natural History of Paget's Disease of Bone in England and Wales
}

\author{
T.P. VAN STAA, ${ }^{1-3}$ P. SELBY, ${ }^{4}$ H.G.M. LEUFKENS, ${ }^{2}$ K. LYLES,,${ }^{5,6}$ J.M. SPRAFKA,${ }^{3}$ and C. COOPER ${ }^{1}$
}

\begin{abstract}
This study used a large, primary care, record-linkage resource (the General Practice Research Database [GPRD]) to evaluate the incidence, clinical presentation, and natural history of Paget's disease of bone in England and Wales. Between 1988 and 1999, we identified 2465 patients with the recorded diagnosis of Paget's disease of bone, within the five million subjects $\geq 18$ years old who were registered in the GPRD. The validity of diagnostic recording was assessed by questionnaire to individual general practitioners (GPs) in 150 patients; the diagnosis was confirmed in $\mathbf{9 3 . 8 \%}$ of responders. The mean age of patients with Paget's disease was $\mathbf{7 5}$ years and $51 \%$ were men. The prevalence of the disorder was $0.3 \%$ among men and women aged $\geq 55$ years; incidence rates for clinically diagnosed Paget's disease rose steeply with age (men, 5 per 10,000 person-years; women, 3 per 10,000 person-years at the age of 75 years). Over the 11-year period of the study, the age- and sex-adjusted incidence rate of clinically diagnosed Paget's disease declined from 1.1 per 10,000 person-years to 0.7 per 10,000 person-years. Each patient with Paget's disease was matched to three controls matched by age, gender, and general practice. Cases had a greater risk of back pain (relative risk [RR], 2.1; 95\% CI, 1.9-2.3), osteoarthritis (OA; RR, 1.7; 95\% CI, 1.5-1.9), hip arthroplasty (RR, 3.1; 95\% CI, 2.4-4.1), knee arthroplasty (RR, 1.6; 95\% CI, 1.0-2.6), fracture (RR, 1.2; 95\% CI, 1.0-1.5), and hearing loss (RR, 1.6; 95\% CI, 1.3-1.9). Seven patients with Paget's disease developed a malignant bone neoplasm $(0.3 \%)$. Using life table methodology, the estimated number of people who died within 5 years of follow-up was $32.7 \%$ among the patients with Paget's disease and 28.0\% among the control patients. (J Bone Miner Res 2002;17:465-471)
\end{abstract}

Key words: Paget's disease, incidence, epidemiology, secular trends, natural history

\section{INTRODUCTION}

$\mathrm{P}$ AGET'S DISEASE of bone (osteitis deformans) is a condition of unknown etiology characterized by rapid bone remodeling and the formation of bone that is structurally

Dr. van Staa and Dr. Sprafka have financial interests in the forms of appointments and stock ownership. Dr. Lyles serves as a consultant. Dr. Selby, Dr. Leufkens, and Dr. Cooper have no conflict of interest. abnormal. ${ }^{(1,2)}$ Epidemiological studies undertaken over the last 30 years have suggested high prevalence rates of radiographic Paget's disease in Britain, with somewhat lower rates in Australia, North America, and parts of western Europe. ${ }^{(3,4)}$ More recent studies in Europe, ${ }^{(5)}$ North America, ${ }^{(6,7)}$ and New Zealand ${ }^{(8)}$ have suggested a decline in the prevalence of Paget's disease with an attenuation of clinical severity at presentation. Although a wide range of clinical manifestations are reported among patients with Paget's disease $^{(1,2,9)}$ including bone pain, fracture, secondary osteo-

\footnotetext{
${ }^{1}$ Medical Research Council Environmental Epidemiology Unit, University of Southampton, Southampton General Hospital, Southampton, United Kingdom.

${ }^{2}$ Department of Pharmacoepidemiology and Pharmacotherapy, Utrecht Institute for Pharmaceutical Sciences, Utrecht, The Netherlands.

${ }^{3}$ Procter \& Gamble Pharmaceuticals, Staines, United Kingdom.

${ }^{4}$ University of Manchester, Manchester, United Kingdom.

${ }^{5}$ GRECC, Veterans Affairs Medical Center, Durham, North Carolina, USA.

${ }^{6}$ Department of Medicine, Duke University Medical Center and Health System, Durham, North Carolina, USA.
} 
arthritis (OA), hearing loss, and syndromes of neurological compression, their frequency in population samples of Paget's disease and the precise increase in risk of these outcomes associated with Paget's disease remain unknown. The objective of this study was to characterize the incidence, clinical features, and outcome of Paget's disease of bone using a large population-based primary care registration system (the General Practice Research Database [GPRD]), which includes information on some five million men and women $\geq 18$ years old in Britain.

\section{MATERIALS AND METHODS}

General practitioners (GPs) play a key role in the healthcare system of the United Kingdom, because they are responsible for primary healthcare and specialist referrals. The data for this study were obtained from the GPRD, which contains the computerized medical records of 683 general practices in the United Kingdom. ${ }^{(10)}$ Approximately $6 \%$ of the total registered population of England and Wales is represented on the database. The data accrued in the GPRD include demographic information about the patient, prescription details, clinical events, preventive care provided, referrals to specialist care, and hospital admissions and their major outcomes. Clinical data are stored and retrieved by means of the Oxford Medical Information Systems (OXMIS) and READ codes for diseases or causes of morbidity and mortality that are cross-referenced to the International Classification of Diseases (ICD-9). The data quality of each entry into GPRD is measured against specific targets developed by comparisons with external statistics to ensure research standards are met. Several independent validation studies have shown that the GPRD has a high level of completeness and validity. ${ }^{(11,12)}$ The GPRD is owned by the Department of Health and managed by the Medicines Control Agency in the United Kingdom.

\section{Study population}

A nonconcurrent (retrospective) cohort study was conducted comparing patients with Paget's disease to control patients. Permanently registered patients $\geq 18$ years old who have Paget's disease recorded during the period of time from the enrollment date of their practice in GPRD up to the end of data collection (July 1999) were selected for the study population. Patients with Paget's disease had a code for Paget's disease in their medical record. Because the coding dictionary does not differentiate between Paget's disease of bone or breast, the free text information at the date of diagnosis had to be reviewed and those with mention of breast or of intraepidermal epithelioma were excluded from the study. Patients with a record of breast carcinoma or intraepidermal epithelioma at any time were excluded also. We attempted to validate the diagnosis of Paget's disease in 150 patients by sending a questionnaire to their GP, which provided details about skeletal symptoms, their location, and the mode of diagnosis.

For each patient with Paget's disease of bone, 3 matched control patients were randomly selected. The control patients were patients without a history of Paget's disease in the medical records who were matched by age (within 1 year), gender, and medical practice. If no control patient was found, the age criterion was expanded consecutively within 1-year intervals up to a 10-year interval. If there was no eligible control patient within 10 years of age, an ageand gender-matched control patient was selected from another practice. About $96 \%$ of cases were matched by age (within 5 years), sex, and practice. The index date of control patients was that of their matched Paget's disease patient (i.e., first record of disease after their enrollment in GPRD). For control patients who had transferred to another practice or died before this date, an index date was selected randomly between registration and transfer dates. Each study patient was followed from the index date until they sustained the outcome event or until the patient's change of practice, death, or the end of the study (whichever date came first).

The outcome events included malignant neoplasm of bone and articular cartilage (ICD-9: 170), cranial nerve disorders (350-352), hearing loss (389), OA (715), hip or knee replacements, and fractures (800-829). The following symptoms also were analyzed: tinnitus (388.3), back pain (724.5), and dizziness and giddiness (780.4). Selected cardiovascular events included hypertensive disease (401405), acute myocardial infarction (410), heart failure (428), and cerebrovascular accident (431-434 and 436). Incidence rates were calculated by dividing the number of patients with the outcome event by the total number of person-years of follow-up. Patients with Paget's disease were compared with controls to estimate the excess risk of the outcome event. We were unable to assess whether fractures occurred at affected skeletal sites.

The age- and sex-specific incidence rates of Paget's disease of bone in the GPRD population were calculated by dividing the number of new cases by the total person-time in the GPRD. The total person-time in the GPRD was the sum of the number of patients registered in the database on July 1 st of each calendar year. Incidence rates over calendar time were estimated also using this number of registered patients. The presence of a linear trend over calendar time was examined using Poisson regression. This model included calendar year, age, and sex. The prevalence of Paget's disease of bone in the GPRD population aged $\geq 55$ years was estimated with the assumption that the population was stable with constant incidence and prevalence rates. Under this steady-state condition, prevalence is equal to the incidence rate divided by the sum of the incidence rate and mortality (termination) rate. ${ }^{(13)}$

The mortality of the Paget's disease and control cohorts was analyzed using Kaplan-Meier survival techniques. Patients were followed over time for survival and censored when they left the practice. Control patients who had transferred to another practice or died before the index date of their matched Paget's disease patient were excluded from this analysis.

\section{RESULTS}

In total, 2465 patients with Paget's disease of bone were included in the study. Figure 1 shows the age- and sex- 


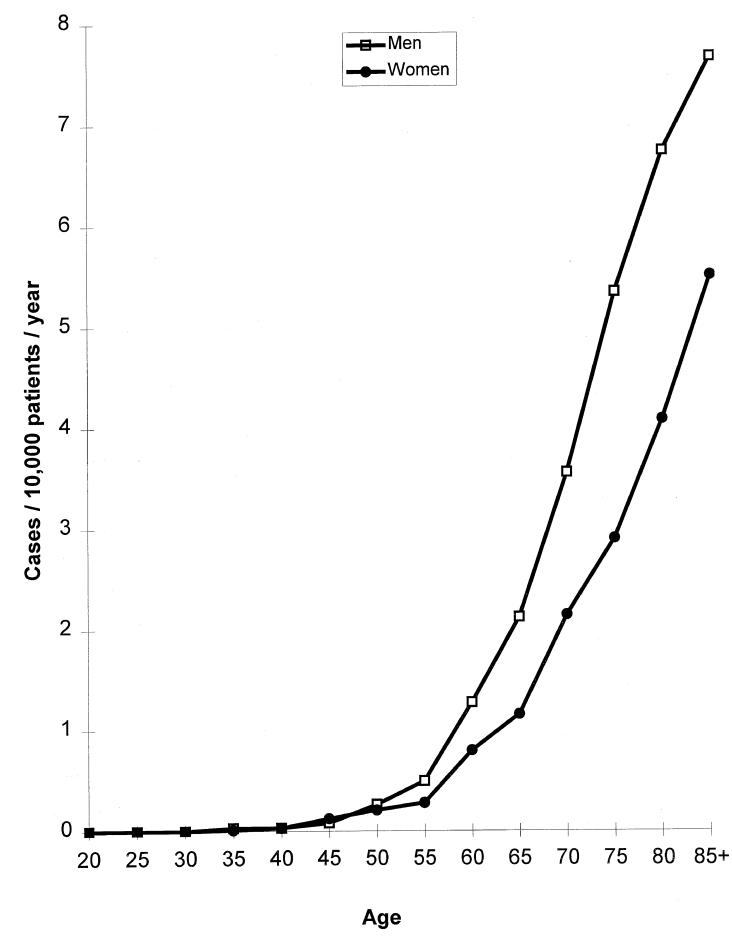

FIG. 1. Age- and sex-specific incidence rate of Paget's disease among five million men and women registered on the GPRD (19881999).

specific incidence of Paget's disease in the adult GPRD population. The disorder was more frequent among men at all ages over 55 years. The incidence increased steeply with age among both men and women. Incidence was 0.3 cases per 10,000 person-years among women aged 55-59 years and 0.5 cases per 10,000 person-years among men of similar age. At the age of $\geq 85$ years, this rate had risen to 5.4 among women and 7.6 among men. We estimated the prevalence of Paget's disease in the GPRD population using the incidence and mortality rates observed in our study. Based on these assumptions, the prevalence of clinically diagnosed Paget's disease is $0.3 \%$ among men and women $\geq 55$ years old. This contrasts with an age- and sexstandardized prevalence rate of $2.0 \%$ in our previous radiographic prevalence survey and suggests that approximately $7 \%$ of cases that are radiographically evident come to clinical diagnosis.

The incidence of Paget's disease of bone in the adult GPRD population decreased significantly over calendar time $(p<0.05)$, as shown in Fig. 2. The incidence was 1.0 cases per 10,000 person-years in 1990 compared with 0.6 cases in 1997. A Poisson regression model with adjustment for age and sex found a statistically significant linear trend of a lower incidence of Paget's disease over calendar time (6\% reduction in the incidence per year). Among the 2465 patients with Paget's disease, the start of GPRD follow-up was distributed as follows: 1987,12 patients $(0.5 \%) ; 1988$, 88 patients (3.6\%); 1989, 344 patients (14.0\%); 1990, 989 patients (40.1\%); 1991, 691 patients $(28.0 \%) ; 1992,162$ patients (6.6\%); 1993, 65 patients (2.6\%); 1994, 53 patients

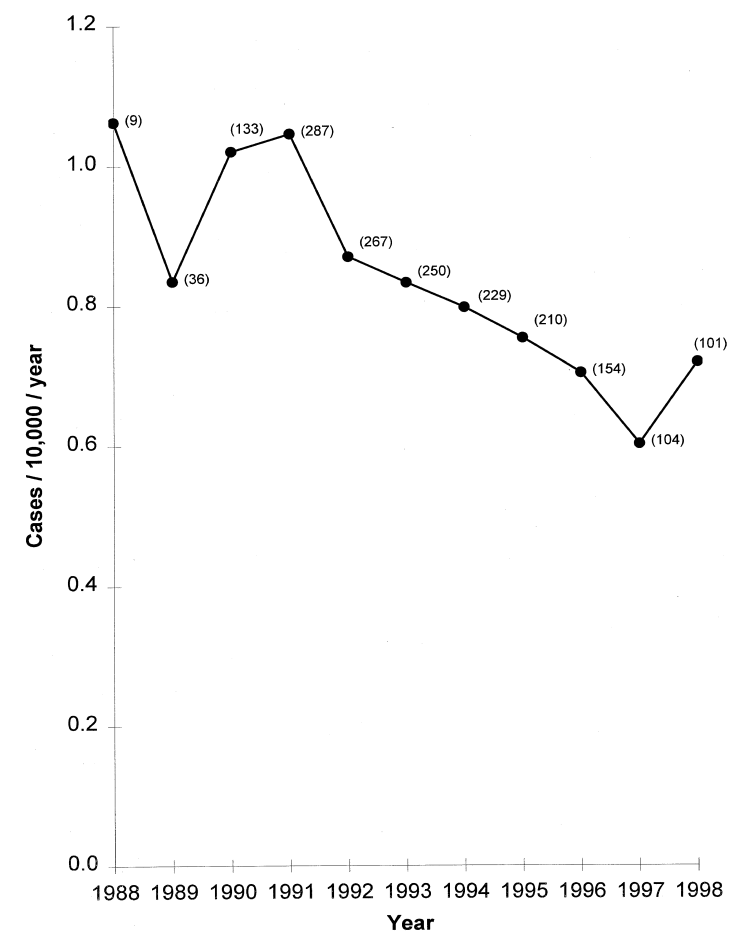

FIG. 2. Decline in age- and sex-standardized incidence rates of Paget's disease in GPRD population (1988-1998).

(2.2\%); 1995, 26 patients $(1.1 \%) ; 1996,15$ patients $(0.6 \%)$, 1997,8 patients $(0.3 \%)$; and 1998,12 patients $(0.5 \%)$. There were no differences between regions in the start of data collection. For the patients with Paget's disease, the median year in which data collection commenced was 1990 in all five regions (southeast, southwest, midlands, east Anglia, and north). The number of patients registered at the GPRD practices did not vary by region over the calendar period covered by the study.

A response to the postal questionnaire was received in 140 of the 150 patients. No further information was available for 7 patients who had either left the practice or died. Of the remaining 133 patients, the diagnosis of Paget's disease of bone was confirmed in 120 patients $(90.2 \%)$. Of the 13 patients without a confirmed diagnosis, 5 patients were found to have breast carcinoma; these patients were excluded from the analysis. Furthermore, 2 patients had suspected Paget's disease, which was not confirmed after further examination. Diagnosis of Paget's disease was made most often by X-ray (85.0\%). Isotope scintigraphy was used in $17.5 \%$ of the patients with a confirmed diagnosis. The method of diagnosis was unknown to the GP in 12 patients $(10.0 \%)$.

Each case with Paget's disease was matched to three controls. As expected, the age and sex distribution was similar between the two groups (Table 1). More than half of the study patients were men and the average age was 75 years. Use of analgesics in the year before commencement of follow-up was higher in the Paget's disease group (an average of 5.2 prescriptions for analgesics in the Paget's disease group and 2.5 prescriptions in the control group). 
Table 1. Characteristics of Paget's Disease and Control Groups

\begin{tabular}{|c|c|c|}
\hline & $\begin{array}{l}\text { Paget's disease group } \\
(\mathrm{n}=2465)\end{array}$ & $\begin{array}{l}\text { Control group } \\
(\mathrm{n}=7395)\end{array}$ \\
\hline \multicolumn{3}{|l|}{ Follow-up } \\
\hline Total duration (person-years) & 7367 & 20,079 \\
\hline Mean duration of follow-up per subject (years) & 3.0 & 2.7 \\
\hline Median duration of follow-up per subject (years) & 2.5 & 2.2 \\
\hline Number of women $(\%)$ & $1213(49.2 \%)$ & $3639(49.2 \%)$ \\
\hline \multicolumn{3}{|l|}{ Age (years) } \\
\hline Mean & 75.0 & 74.7 \\
\hline Median & 76 & 75 \\
\hline \multicolumn{3}{|c|}{ Use of analgesics 1 year before NSAID, aspirin, and other analgesics } \\
\hline Mean number of prescriptions for analgesics & 5.2 & 2.5 \\
\hline
\end{tabular}

NSAID, nonsteroidal anti-inflammatory drug.

Table 2. Frequency of Selected Events in Paget's Disease and Control Groups

\begin{tabular}{|c|c|c|c|c|c|c|}
\hline & \multicolumn{2}{|c|}{$\begin{array}{l}\text { Paget's disease group } \\
\quad(\mathrm{n}=2465)\end{array}$} & \multicolumn{2}{|c|}{$\begin{array}{l}\text { Control group } \\
(\mathrm{n}=7395)\end{array}$} & \multirow{2}{*}{$\begin{array}{l}\text { Crude relative } \\
\text { rate }\end{array}$} & \multirow[b]{2}{*}{$95 \% C$} \\
\hline & No. of cases & Rate (\%) & No. of cases & Rate (\%) & & \\
\hline Back pain & 601 & 10.2 & 887 & 4.9 & 2.1 & $1.9-2.3$ \\
\hline $\mathrm{OA}$ & 352 & 5.6 & 619 & 3.4 & 1.7 & $1.5-1.9$ \\
\hline Dizziness/giddiness & 322 & 5.0 & 678 & 3.7 & 1.3 & $1.2-1.5$ \\
\hline Fracture & 194 & 2.8 & 437 & 2.3 & 1.2 & $1.0-1.5$ \\
\hline Femur/hip fracture & 71 & 1.0 & 137 & 0.7 & 1.4 & $1.1-1.9$ \\
\hline Hearing loss & 170 & 2.4 & 296 & 1.5 & 1.6 & $1.3-1.9$ \\
\hline Hip arthroplasty & 104 & 1.5 & 93 & 0.5 & 3.1 & $2.4-4.1$ \\
\hline Knee arthroplasty & 25 & 0.3 & 43 & 0.2 & 1.6 & $1.0-2.6$ \\
\hline Tinnitus & 47 & 0.6 & 85 & 0.4 & 1.5 & $1.1-2.2$ \\
\hline Cranial nerve disorder & 17 & 0.2 & 39 & 0.2 & 1.2 & $0.7-2.1$ \\
\hline Malignant neoplasm bone & 7 & 0.1 & 0 & 0 & $\infty$ & $5.0-\infty$ \\
\hline
\end{tabular}

Bisphosphonates were prescribed to 664 patients with Paget's disease $(26.9 \%)$. During follow-up, calcitonin was prescribed to 179 patients $(7.3 \%)$. In the questionnaire study of $150 \mathrm{GPs}$, bone pain was the most frequently reported symptom $(66.7 \%)$, followed by bone deformity $(9.2 \%)$, and swelling (9.2\%). The GPs reported that $13.3 \%$ of the Paget's patients were asymptomatic. The most frequently reported locations of Paget's disease were pelvis (47.5\%), femur (25.8\%), tibia/fibula (21.7\%), and lumbar spine (19.2\%).

$\mathrm{OA}$ and hip/knee arthroplasty were among the events that occurred more frequently in the Paget's disease group (Table 2). The relative rate (RR) for hip arthroplasty was 3.1 in the Paget's disease group compared with controls. The RRs for knee arthroplasty and OA were 1.6 and 1.7, respectively. Patients with Paget's disease had a $44 \%$ increased risk of hip fracture. Seven patients with Paget's disease developed a malignant bone neoplasm during follow-up (incidence rate, 0.1 per 100 person-years). Five of these cases were documented as osteosarcomata in the medical records, and all were fatal. The other two cases of malignant bone neoplasm were classified as chondrosarcomata.

Table 3 shows the rate of cardiovascular events among patients with Paget's disease and controls. Patients with Paget's disease experienced higher rates of heart failure
(RR, 1.2). There were no statistically significant differences between the groups in the rates of ischemic heart disease, cerebrovascular accident, or hypertension.

A total of 616 patients with Paget's disease died during follow-up. Figure 3 shows the survival of Paget's disease and control patients over 5 years of follow-up. After 5 years, $32.7 \%$ of the Paget's disease group had died compared with $28.0 \%$ of the control group (RR, 1.3; 95\% CI, 1.1-1.4). Restriction of the analysis to cases and controls matched within 1 year of age did not change results (RR, 1.4; 95\% CI, 1.2-1.5). The three most frequent causes of death during follow-up in the Paget's disease group were diseases of the circulatory system (37.9\%), neoplasms $(21.8 \%)$, and diseases of the respiratory system $(20.9 \%)$. The RRs of these three causes of death in the Paget's disease group compared with the control group were 1.5 (95\% CI, 1.3-1.7), 1.8 (95\% CI, 1.5-2.2), and 1.3 (95\% CI, 1.1-1.6), respectively.

\section{DISCUSSION}

This population-based study of Paget's disease suggests that approximately $0.3 \%$ of British men and women who were $\geq 55$ years old have clinically diagnosed Paget's dis- 
Table 3. Frequency of Cardiovascular Events in Paget's Disease and Control Groups

\begin{tabular}{|c|c|c|c|c|c|c|}
\hline & \multicolumn{2}{|c|}{$\begin{array}{l}\text { Paget's disease group } \\
\qquad(\mathrm{n}=2465)\end{array}$} & \multicolumn{2}{|c|}{$\begin{array}{l}\text { Control group } \\
(\mathrm{n}=7395)\end{array}$} & \multirow{2}{*}{$\begin{array}{c}\text { Crude relative } \\
\text { rate }\end{array}$} & \multirow[b]{2}{*}{$95 \% \mathrm{Cl}$} \\
\hline & No. of cases & Rate (\%) & No. of cases & Rate (\%) & & \\
\hline Heart failure & 315 & 4.6 & 706 & 3.7 & 1.2 & $1.1-1.4$ \\
\hline Hypertensive disease & 291 & 4.4 & 794 & 4.4 & 1.0 & $0.9-1.2$ \\
\hline Acute myocardial infarction & 103 & 1.4 & 345 & 1.7 & 0.8 & $0.7-1.0$ \\
\hline Cerebrovascular accident & 154 & 2.1 & 421 & 2.1 & 1.0 & $0.8-1.2$ \\
\hline
\end{tabular}

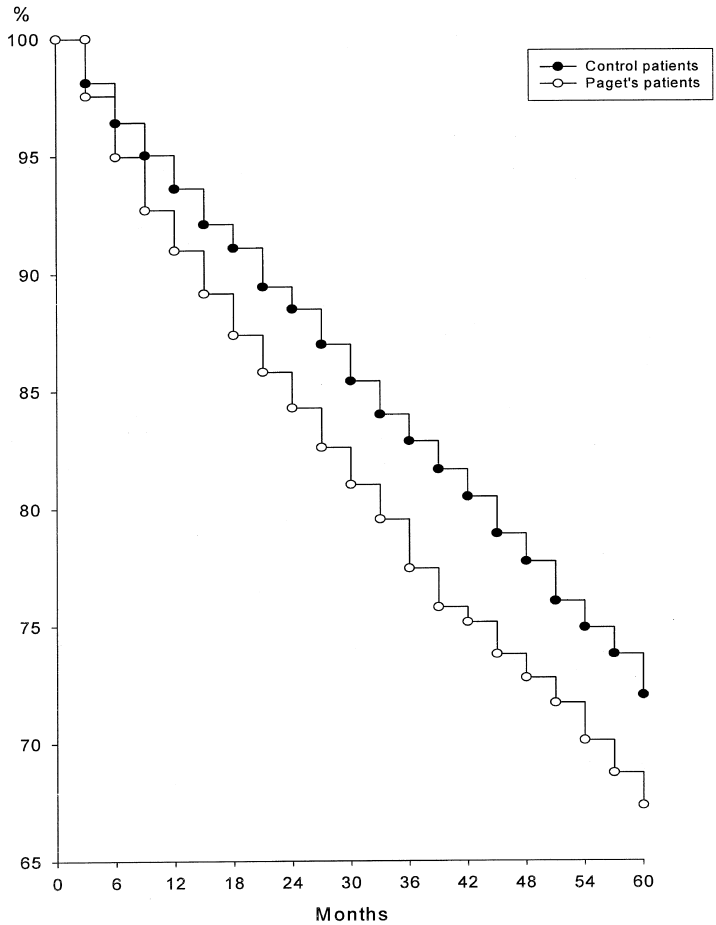

FIG. 3. Survival over 5 years after clinical diagnosis among 2465 patients with Paget's disease and 7395 controls registered in the GPRD.

ease of bone. The incidence rate of Paget's disease rises steeply with age among men and women. Patients with Paget's disease were at significantly increased risk of back pain, OA leading to hip and knee arthroplasty, fracture, hearing loss, and heart failure. Approximately $0.3 \%$ of our sample developed a malignant bone neoplasm over the follow-up period.

Our study was able to provide estimates of the risk of a range of complications among patients with clinically diagnosed Paget's disease. The skeletal complications of this disorder are well known and include fractures, deafness, OA, and sarcomatous change. ${ }^{(1,2,9)}$ In our study, we found an excess fracture rate of 0.5 per 100 person-years; this is in agreement with an incidence of 1.2 fractures through Pagetic bone per 100 person-years in a population-based cohort study, ${ }^{(9)}$ a previous analysis of clinical trial data that suggested a rate of 2.3 fractures per 100 person-years among patients with Paget's disease, ${ }^{(14)}$ and a questionnaire survey that documented a greater frequency of reported previous fracture among patients $(41 \%)$ than among controls $(33 \%){ }^{(6)}$ Information on deafness among patients with Paget's disease is only available from case series in the literature. $^{(15-17)}$ These suggest that between $13 \%$ and $23 \%$ of patients with clinically diagnosed Paget's disease suffer from impaired hearing. In our study, $15.9 \%$ of the Paget's disease cases reported deafness at any time in their medical record, compared with $10 \%$ of the controls. Data also are scarce on the excessive risk of OA associated with Paget's disease. One study has reported that hip OA was more severe on the affected side than on the contralateral side. ${ }^{(18)}$ Our estimate of $36.6 \%$ for OA among patients with clinically diagnosed Paget's disease was lower than the frequency observed in a published North American questionnaire-based survey ${ }^{(6)}$; however, the difference in fracture frequency between patients with Paget's disease and controls was similar in the two reports. Because of its poor prognosis, sarcomatous change of pagetic bone is one of the most feared complications of Paget's disease. ${ }^{(19-21)}$ Reports in the literature have placed the incidence of malignant bone tumors between $0.7 \%$ and $1.0 \%$ among patients with Paget's disease.

Our study agrees with previous epidemiological investigations, suggesting a steep increase in the frequency of Paget's disease of bone with advancing age in both sexes and greater incidence rates among elderly men than elderly women. ${ }^{(3-5,7)}$ The Rochester study found an incidence of clinically symptomatic Paget's disease of 1.3 per 10,000 person-years among men and 0.7 per 10,000 person-years among women. ${ }^{(7)}$ The most recent prevalence data from the Britain were obtained in a radiographic survey that suggested that involvement was apparent in radiographs of $0.3 \%$ of men and women aged 55-59 years, rising to $6.9 \%$ of men and $5.8 \%$ of women who were $\geq 85$ years old. ${ }^{(5)}$ The age- and sex-adjusted prevalence of Paget's disease in this survey was $6 \%$ in patients who were $\geq 75$ years old, suggesting that approximately $7 \%$ of patients with the disorder apparent on radiographs reached clinical diagnosis in the British primary and secondary healthcare system. There are few data in the literature on the proportion of patients with radiographic Paget's disease who developed symptoms. A synthesis of clinical studies estimated that symptomatic disease could account for $5 \%$ of the total population of patients with Paget's disease, ${ }^{(22)}$ a proportion in keeping with the results of our own study. Extrapolation from our data to the total population of England and Wales suggests 
that approximately 19,000 men and 21,000 women currently have symptomatic Paget's disease in England and Wales. We also found that the incidence of Paget's disease decreased by approximately $35 \%$ over an 11-year period of follow-up. Secular trends in disease are difficult to characterize using primary care registration systems, because changes in clinical and diagnostic practice may influence apparent incidence estimates. Because we did not have lifetime data, we also were unable to exclude the possibility that the early incidence rates were inflated by prevalent cases, that is, those known before 1988 but recorded with a first diagnosis in GPRD after 1988. However, the recording rules of the GPRD instruct GPs to record the date of original onset of any chronic or recurrent conditions. Nevertheless, our findings are consistent with the recently reported British study that suggested that the prevalence of radiographic Paget's disease had decreased by approximately $60 \%$ between 1974 and 1994. ${ }^{(5)}$ This temporal trend may be caused by a change in the natural history of Paget's disease, with less severe disease observed at onset, ${ }^{(2)}$ a possibility supported by a New Zealand study ${ }^{(8)}$ and by the Rochester study. ${ }^{\text {(7) }}$ However, data from four Spanish centers suggested an increase in the frequency of clinically diagnosed Paget's disease of $54 \%$ over a 5 -year period. ${ }^{(23)}$ Support for the declining incidence and severity of the disorder also comes from mortality studies of Paget's disease and of malignant bone tumors. ${ }^{(24)}$

There are several limitations of this study. First, Paget's disease often was coded without specification as to its anatomical site (bone or breast). We excluded 169 patients (6.4\% of the total number of Paget's disease cases) on the basis that their medical record information indicated involvement of the breast. However, when we examined the relationship of clinically diagnosed Paget's disease with various clinical outcomes, the inclusion of these subjects did not materially alter the results, suggesting that any bias due to the nonspecific coding of Paget's disease is likely to be small. Our validation study of diagnostic coding suggested that the diagnosis primarily had been made based on radiographic evidence. However, we did not have access to the radiographs and could not confirm the reproducibility of this radiographic grading and the precise skeletal location of the disease. The most likely effect of such misclassification would be an underestimate of the risk of Paget's disease, because of inclusion of any questionable cases. A third limitation concerns surveillance bias. Patients with Paget's disease may have received more frequent medical supervision because of their disease, possibly leading to a higher likelihood of diagnosis of the index condition, as well as of other medical outcomes. This bias is particularly relevant for conditions that do not require that patients seek medical attention.

In conclusion, this British population-based study of Paget's disease of bone suggests that the incidence rate of clinically diagnosed cases rises steeply with age among men and women and is greater among elderly men. Comparison of the prevalence of clinically diagnosed Paget's disease $(0.3 \%$ among men and women who were $\geq 55$ years old $)$ with prevalence estimates of radiographic disease suggests that approximately $7 \%$ of radiographic disease comes to clinical diagnosis. The study provides comparative data on the frequency of a broad group of outcomes including auditory impairment, OA, fracture, and congestive cardiac failure. Although the incidence rates of clinically diagnosed Paget's disease do appear to be declining over calendar time during the 10 years, our data suggest that 19,000 men and 21,000 women in England and Wales suffer from clinically diagnosed Paget's disease, and therapeutic studies of intervention in this group to reduce the incidence of complications appear to be warranted.

\section{ACKNOWLEDGMENTS}

We thank Epidemiology and Pharmacology Information Coral (EPIC), the GPRD license holder, for their support. This article was prepared by Gill Strange. Funds for this study were provided through a grant by Procter \& Gamble Pharmaceuticals. K.W.L. was supported by grants AG11268 from the VA Medical Research Service and RR30 from the Division of Research Resources, National Institutes of Health (NIH).

\section{REFERENCES}

1. Papapoulos SE 1997 Paget's disease of bone: Clinical, pathogenetic and therapeutic aspects. Ballieres Clin Endocrinol Metab 11:117-143.

2. Ooi CG, Fraser WD 1997 Paget's disease of bone. Postgrad Med J 73:69-74.

3. Cooper C, Dennison E, Schafheutle K, Kellingray S, Guyer P, Barker D 1999 Epidemiology of Paget's disease of bone. Bone 24(Suppl):3S-5S.

4. Barker DJP 1984 The epidemiology of Paget's disease of bone. BMJ 40:396-400.

5. Cooper C, Schafheutle K, Dennison E, Kellingray S, Guyer P, Barker D 1999 The epidemiology of Paget's disease in Britain: Is the prevalence decreasing? J Bone Miner Res 14:192-197.

6. Siris ES 1994 Epidemiological aspects of Paget's disease: Family history and relationship to other medical conditions. Semin Arthritis Rheum 222-225.

7. Tiegs RD, Lohse CM, Wollan PC, Melton LJ III 2000 Longterm trends in the incidence of Paget's disease of bone. Bone 27:423-427.

8. Cundy T, McAnulty K, Wattie D, Gamble G, Rutland M, Ibbertson HK 1997 Evidence for secular change in Paget's disease. Bone 20:69-71.

9. Melton LJ III, Tiegs RD, Atkinson EJ, O'Fallon WM 2000 Fracture risk among patients with Paget's disease: A populationbased cohort study. J Bone Miner Res 15:2123-2128.

10. Walley T, Mantgani A 1997 The UK General Practice Research Database. Lancet 350:1097-1099.

11. Jick H, Jick SS, Derby LE 1991 Validation of Information recorded on general practitioner based computerised data resource in the United Kingdom. BMJ 302:766-768.

12. van Staa TP, Abenhaim L, Cooper C, Begaud B, Zhang B, Leufkens HGM 2000 The use of a large pharmacoepidemiological database to study exposure to oral corticosteroids and risk of fractures: Validation of study population and results. Pharmacoepidemiol Drug Saf 9:359-366.

13. Kleinbaum DG, Kupper LL, Morgenstern H 1982 Other measures of disease frequency. In: Epidemiologic Research: Principles and Quantitative Methods. Van Norstrand Reinhold Company, Inc., New York, NY, USA, pp. 120-122. 
14. Johnston CC, Altman RD, Canfield RE, Finerman GAM, Taulbee JD, Ebert ML 1983 Review of fracture experience during treatment of Paget's disease of bone with etidronate sodium (EHDP). Clin Orthop 172:186-194.

15. Rosenkrantz JA, Wolf J, Kaicher JJ 1952 Paget's disease (osteitis deformans): Review of one hundred eleven cases. Arch Intern Med 90:610-633.

16. Gutman AB, Kasabach H 1936 Paget's disease (osteitis deformans): Analysis of 116 cases. Am J Med Science 191:361380.

17. Hamdy RC, Moore S, LeRoy J 1993 Clinical presentation of Paget's disease of the bone in older patients. South Med J 86:1097-1100.

18. Helliwell PS 1995 Osteoarthritis and Paget's disease. Br J Rheumatol 34:1061-1063.

19. Wick MR, Siegal GP, Unni KK, McLeod RA, Greditzer HG 1981 Sarcomas of bone complicating osteitis deformans (Paget's disease): Fifty years' experience. Am J Surg Pathol 5:47-59.

20. Greditzer HG, McLeod RA, Unni KK 1983 Bone sarcomas in Paget's disease. Radiology 146:327-333.

21. Hadjipavlou A, Lander P, Srolovitz H, Enker IP 1992 Malignant transformation in Paget's disease of bone. Cancer 70: 2802-2808.
22. Kanis JA 1991 Clinical features and complicatoins. In: Pathophysiology and Treatment of Paget's Disease of Bone. Dunitz, London, UK, pp. 110-138.

23. Rapado A, Jimenez J, Morales A, Carbonell J, Del Pino J 1999 Patterns of diagnosis of Paget's disease in Spain. J Bone Miner Res 14:S2;S96-S98.

24. Gardner MJ, Barker DJP 1978 Mortality from malignant tumours of bone and Paget's disease in the United States and in England and Wales. Int J Epidemiol 7:121-130.

Address reprint requests to:

Prof. Cyrus Cooper, M.A., D.M., F.R.C.P. MRC Environmental Epidemiology Unit Southampton General Hospital Southampton SO16 6YD, UK

Received in original form March 9, 2001; in revised form September 10, 2001; accepted October 22, 2001. 